\title{
Evaluasi Kesuksesan Implementasi SLA Pada Mobile PLIK Bangka Belitung
}

\author{
Ellya Helmud*1 ${ }^{1}$, Harrizki Arie Pradana ${ }^{2}$, Parlia Romadiana ${ }^{3}$ \\ ${ }^{1,2,3}$ ISB Atma Luhur; Jl.Jend. Sudirman Kel.Selindung Kec.Gabek Pangkalpinang, \\ (0717) 433506 \\ ${ }^{1,2}$ Program Studi Teknik Informatika, ${ }^{3}$ Program Studi Manajemen Informatika, \\ FTI ISB Atma Luhur, Pangkalpinang \\ e-mail: ${ }^{1}$ ellyahelmud@atmaluhur.ac.id, *2harrizkiariep@atmaluhur.ac.id, \\ 3parliaromadiana@atmaluhur.ac.id
}

\begin{abstract}
Abstrak
Teknologi informasi yang berkembang saat ini tidak hanya berlaku di dunia teknologi informasi saja, akan tetapi sudah berkembang ke bidang perkerjaan yang lainnya yang membutuhkan sebuah teknologi informasi untuk mendukung kebutuhan bidang mereka. Pelayanan pada teknologi informasi ini telah diterapkan oleh Pusat Layanan Internet Kecamatan (PLIK) Bangka Belitung untuk mendukung program pemerintah. Penelitian yang dilakukan di PLIK, bertujuan untuk melihat dan menilai bagaimana kinerja PLIK terutama Mobile PLIK terhadap tingkat layanan kepuasan mitra mereka. Selama penelitian di PLIK, peneliti ingin mengukur tingkat layanan mereka. Tingkat layanan yang diukur adalah dengan melihat implementasi SLA (Service Level Agreement) yang mereka kontrakan dengan pengguna sudah sejauh mana. Maka peneliti mengambil data dengan observasi, wawancara, maupun kuesioner. Setelah semua data diperlukan ada, Framework COBIT 4.0 menjadi acuan peneliti untuk meneliti tingkat layanan ini dengan domain Delivery and Support (DS) pada tiap butirnya. Kesimpulan yang didapat dari keseluruhan proses penelitian adalah Mobile PLIK sudah mengukur tingkat kedewasaan pelayanan (Maturity Level) mereka pada layer 4, yaitu Managed and Measurable Namun, ada beberapa Kabupaten yang masih pada layer 3, yaitu Define. Define yaitu mereka telah menargetkan dan merencanakan setiap langkah kerja mereka terukur dan tentunya bisa meningkatkan pelayanan yang diberikan kepada mitra dan menjadi timpal balik terhadap kepuasan mitra terhadap PLIK. Berbeda halnya dengan Define, layer 4 Managed and Measurable yang berarti Mobile PLIK telah tertata dan bisa diukur dalam melakukan tiap perjanjian antara mitra dengan PLIK, sehingga setiap butir pada domain bisa dipertanggungjawabkan implementasinya.
\end{abstract}

Kata kunci-Mobile PLIK, SLA, Framework COBIT 4.0, Delivery Support Domain, RACI Charts.

\begin{abstract}
Information technology that is currently developing does not only apply to the world of information technology but has developed into other fields of work that require information technology to support the needs of their field. Services in information technology have been implemented by the District Internet Service Center (PLIK) Bangka Belitung to support government programs. Research conducted at PLIK, aims to see and assess how PLIK's performance, especially Mobile PLIK, to the service level of their partners' satisfaction. During the PLIK research, researchers wanted to measure their level of service. The level of service that is measured is by looking at the implementation of the SLA (Service Level Agreement) that they have contracted with the user to what extent. So, the researchers took the data by observation, interviews, and questionnaires. After all data is needed, the COBIT 4.0 Framework becomes a reference for researchers to examine this service level with the Delivery and Support
\end{abstract}


(DS) domain on each item. The conclusion from the whole research process is that Mobile PLIK has measured their service maturity level (Maturity Level) at layer 4, namely Managed and Measurable. However, there are several districts that are still at layer 3, namely Define. Define that they have targeted and planned every measure of their work steps and of course they can improve the services provided to partners and be reciprocal to partner satisfaction with PLIK. Unlike the case with Define, layer 4 is Managed and Measurable, which means that Mobile PLIK has been organized and can be measured in conducting every agreement between partners and PLIK, so that its implementation can be accounted for every item in the domain.

Keywords-Mobile PLIK, SLA, Framework COBIT 4.0, Delivery Support Domain, RACI Charts.

\section{PENDAHULUAN}

PLIK atau Pusat Layanan Internet Kecamatan adalah suatu lembaga yang didirikan oleh Kementerian Teknologi Informasi dan Komunikasi (KemKomInfo) yang berfungsi sebagai penyelenggara jaringan internet yang bertanggung jawab pada setiap kecamatan di seluruh kabupaten dan provinsi yang ditanganinya, dalam hal ini provinsi Bangka Belitung. Untuk melayani wilayah kecamatan yang belum terjangkau PLIK Bangka Belitung, diimplementasikan PLIK Keliling (MPLIK) yang mobil tapi sehat, aman, cepat, dan murah. Ketentuan PLIK mobil (MPLIK) tertuang dalam Pasal 5 Peraturan Menteri Komunikasi dan Informatika Nomor 48 / PER / M.KOMINFO / 11/2009 tentang Penyelenggaraan Layanan Akses Internet di Wilayah Pelayanan Universal Telekomunikasi Internet Kabupaten. sebagaimana telah diubah dengan Peraturan Menteri Komunikasi dan Informatika Nomor 19 / PER / M.KOMINFO / 12/2010.

Service Level Agreement (SLA) sebagai pedoman penyelarasan kinerja PLIK mobil (MPLIK) diprioritaskan untuk mencapai target yang disepakati antara mitra dan penyedia (PLIK Bangka Belitung). Menurut [1], SLA merupakan perjanjian kontrak antara dua pihak yaitu pelanggan dan penyedia layanan. Kesepakatan dalam hal ini dapat berupa kontrak formal dan informal. SLA merupakan alat untuk mengukur dan mengendalikan proses bisnis yang terjadi dalam suatu pekerjaan, sehingga memudahkan untuk mengevaluasi dan meningkatkan proses bisnis yang bersangkutan. Beberapa hal yang mungkin ada dalam suatu SLA antara lain ketersediaan layanan (\%), jumlah pelanggan yang dapat dilayani secara bersamaan, laporan pencapaian target yang disampaikan secara berkala, dan waktu pengoperasian helpdesk. Untuk itu diperlukan penelitian agar hasil yang diperoleh dapat kemudian diimplementasikan.

Pertanyaan-pertanyaan berikut yang merupakan poin-poin utama keberhasilan pencapaian target MPLIK dalam SLA. Apakah operasional dapat berjalan dengan lancar jika pengadaan yang ada di PLIK sendiri sudah tidak tersedia lagi? Lalu apakah pengadaan dapat berjalan lancar tetapi operasional tidak tersedia, bila operasional dan pengadaan hasil sesuai target? Dan apakah penerapan SLA di MPLIK Bangka Belitung sudah efektif? Dan untuk mengetahui seperti apa tingkat kematangan proses teknologi informasi saat ini dan yang diharapkan di PLIK Bangka Belitung terkait dengan dukungan layanan teknologi informasi, terutama bila terjadi gangguan akibat kesalahan manusia dan teknis. Dibutuhkan batasan masalah yang akan ditetapkan sebagai tolok ukur keputusan target analisis, berikut ini batasan masalah yang dapat diambil, faktor keamanan informasi dalam SLA tetap terjaga. Dalam lingkup bermitra dengan PLIK saja, tidak termasuk PLIK dengan mitra penyedia layanan jaringan, dan PLIK Bangka Belitung dengan pusat PLIK yang berlokasi di Jakarta. Model kompilasi yang berfokus pada aspek spesifik layanan TI, mendefinisikan dan memberikan dukungan layanan TI kepada manajemen. Fokus pada tahap solusi yang diharapkan yang 
menentukan tingkat kematangan nilai dari setiap tujuan pengendalian, menentukan pengujian hipotesis dan tahap perencanaan solusi. Framework COBIT 4.0 hanya digunakan oleh satu domain, yaitu Delivery and Support (DS).

Tujuan dari penelitian yang dilakukan adalah untuk mengetahui apakah target dan objek PLIK tercapai atau tidak kepada mitranya sehingga memudahkan kinerja dan layanan yang telah diatur dalam service level agreement (SLA) antara keduanya. pihak dan untuk memastikan pemantauan dan pelaporan kinerja tepat waktu. Mengetahui sesuai dengan bidangnya dan apakah targetnya sudah tercapai atau tidak terhadap PLIK itu sendiri. Mengidentifikasi permasalahan dalam pelaksanaan aktivitas TI, terutama pada proses pendefinisian dan pengelolaan layanan dukungan yang mengacu pada COBIT 4.0 Framework pada domain Deliver and Support (DS). Manfaat yang diambil dari penelitian ini antara lain dapat memberikan masukan dan mengetahui sejauh mana kinerja PLIK selama ini sudah tercapai atau belum, selain itu juga mereka dapat menambah wawasan tentang service level management (SLM) dengan mencapai service level agreement (SLA) yang telah disepakati kedua belah pihak dalam suatu organisasi atau lembaga.

Katalog layanan menentukan semua layanan yang diberikan organisasi kepada pelanggannya, dan SLA (Perjanjian Tingkat Layanan) menentukan tingkat ukuran yang disepakati untuk masing-masing layanan ini [2]. Service Level Agreement (SLA) disepakati dan ditandatangani antara organisasi dan pelanggannya, mengenai layanan yang diberikan bersama dengan ukuran atau level atau level atau metrik dari setiap aspek layanan. Layanan adalah cara untuk menyampaikan nilai kepada pelanggan dengan memfasilitasi pencapaian hasil yang diinginkan kepada mereka, tanpa harus menanggung risiko dan biaya yang tidak perlu sendiri [3]. Menurut ITIL (Information Technology Infrastructure Library) v3, katalog layanan adalah [4]:

a. Database atau dokumen terstruktur dengan informasi tentang semua layanan teknologi informasi yang tersedia, termasuk yang siap diluncurkan

b. Merupakan bagian dari portofolio layanan yang dipublikasikan kepada pelanggan

c. Digunakan sebagai alat untuk mendukung penjualan dan penyampaian layanan teknologi informasi kepada pelanggan

d. Termasuk informasi tentang kiriman (diperoleh pelanggan), harga dan tarif, detail kontak, cara memesan dan cara meminta (permintaan).

SLA merupakan bagian dari keseluruhan perjanjian pelayanan (agreement) antara 2 (dua) entitas untuk peningkatan kinerja atau waktu pelayanan harus diperbaiki selama masa kontrak, kesepakatan dalam hal ini dapat berupa kontrak formal dan informal. SLA juga merupakan alat untuk mengukur dan mengendalikan proses bisnis yang terjadi dalam suatu pekerjaan, sehingga memudahkan untuk mengevaluasi dan meningkatkan proses bisnis yang bersangkutan. Perjanjian Tingkat Layanan (SLA) merupakan bagian integral dari kontrak vendor mana pun. Selain mencantumkan ekspektasi kualitas dan jenis layanan, SLA menawarkan perbaikan ketika satu pihak gagal memenuhi semua persyaratan yang disebutkan.

Jadi kesimpulannya, SLA adalah kontrak atau kesepakatan antara perusahaan dan penyedia layanannya yang menyatakan secara rinci harapan dan kewajiban dari hubungan tersebut. Ada beberapa keuntungan bekerja sama dengan penyedia layanan, tetapi untuk mendapatkan hasil maksimal dari jenis kemitraan ini, SLA harus diterapkan. Menurut [5], SLA bertindak sebagai cetak biru layanan yang disediakan vendor dan dapat melindungi aset dan reputasi perusahaan Anda. Meskipun SLA telah ada selama beberapa waktu, mereka menjadi lebih populer sekitar 10 tahun yang lalu ketika outsourcing mulai mendominasi industri TI. Berikut adalah komponen-komponen dari SLA menurut [6]:
a. Jasa,
b. Pengukuran,
c. Interval, 
d. Kewajiban, dan

e. Hukuman.

Dalam teori yang mengungkapkan Kerangka COBIT 4.0 dapat diambil dari [7] "Perusahaan membutuhkan model tata kelola yang kuat untuk menyelaraskan investasi TI dengan kebutuhan bisnis. Proses bisnis dalam TI di Unisys telah meningkat karena menggunakan COBIT untuk kepatuhan Sarbanes-Oxley yang sedang berlangsung dan proyek terkait tata kelola TI lainnya. "

[1] mengatakan, "COBIT dan Val IT digunakan di seluruh dunia untuk memastikan bahwa teknologi informasi memberikan nilai dan mendukung strategi perusahaan, sambil menggunakan sumber daya dengan bijak, memitigasi risiko dan mengukur kinerja." Framework COBIT 4.0 merupakan standar internasional lengkap yang dituangkan dalam bentuk worksheet (kerangka kerja) yang dapat digunakan dan memudahkan manajemen untuk memastikan kinerja teknologi informasinya dalam membantu mereka mencapai target dan penilaian [7].

Kerangka kerja ini memastikan bahwa ia bekerja seefektif mungkin untuk meminimalkan risiko hubungan antar teknologi informasi dan memaksimalkan manfaat yang diperoleh dari budidaya teknologi informasi. COBIT juga menjadi jembatan gap antara bisnis dan teknologi informasi [4]. Deliver and Support adalah domain dalam pengembangan Define and Manage Service Levels dalam COBIT 4.0 Framework [8]. Komunikasi yang efektif antara manajemen teknologi informasi dan pelanggan bisnis dengan mendefinisikan pemahaman dan kesepakatan dalam layanan teknologi informasi dan tingkat layanan. Proses ini juga mencakup pemantauan kepada pemilik perusahaan dan pelaporan secara berkala. Proses ini terjadi antara teknologi informasi yang saling berhubungan dan layanan bisnis. Untuk dapat memahami kerangka kerja COBIT, perlu diketahui bahwa COBIT mempunyai karakteristik utama. Adapun karakteristik utama dari kerangka kerja COBIT adalah fokus pada bisnis, orientasi pada proses, berbasis kontrol dan dikendalikan oleh pengukuran [9].

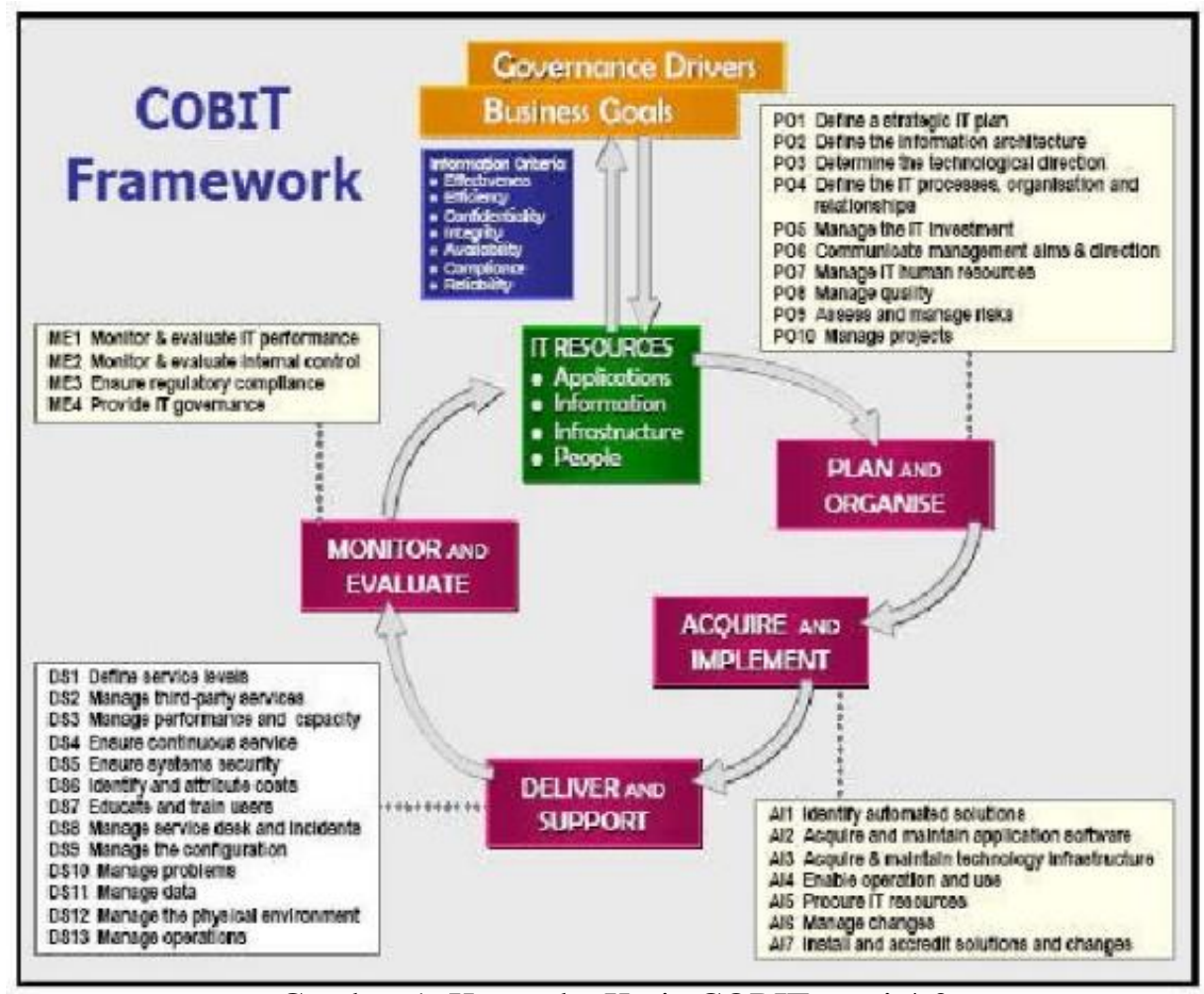

Gambar 1. Kerangka Kerja COBIT versi 4.0 
Domain Delivery and Support (DS) ini menekankan pada proses layanan TI dan dukungan teknis yang meliputi hal-hal keamanan sistem, kontinuitas layanan, pelatihan dan edukasi bagi pengguna, dan pengelolaan data yang sedang berjalan [10]. Domain DS terdiri dari 13 tujuan pengendalian, yaitu:

a. DS1 - Tentukan dan kelola tingkat layanan.

b. DS2 - Kelola layanan pihak ketiga.

c. DS3 - Kelola kinerja dan kapasitas.

d. DS4 - Pastikan layanan berkelanjutan.

e. DS5 - Pastikan keamanan sistem.

f. DS6 - Identifikasi dan alokasikan biaya.

g. DS7 - Mendidik dan melatih pengguna.

h. DS8 - Kelola meja layanan dan insiden.

i. DS9 - Kelola konfigurasi.

j. DS10 - Kelola masalah.

k. DS11 - Kelola data.

1. DS12 - Kelola lingkungan fisik.

m. DS13 - Kelola operasi.

Adapun perbedaan antara Framework COBIT 5 dengan COBIT versi 4.0 diantaranya adalah menyediakan input dan output untuk setiap management practice bagi kerangka kerja COBIT 5, sementara COBIT 4.0 hanya menyediakan ini pada tingkatan proses saja per tiap domain pada tubuh mereka [11].

\section{METODE PENELITIAN}

\subsection{Tipe Metode Penelitian}

Penelitian ini merupakan kegiatan dan metode berfikir yang digunakan untuk mengevaluasi tingkat kematangan PLIK mobile Provinsi Bangka Belitung. Jika dilihat dari rumusan masalah, penelitian ini akan memberikan gambaran jawaban melalui alat ukur kemudian diolah sesuai dengan kerangka kerja COBIT. Teknik statistik penelitian deskriptif biasanya digunakan apabila tujuan penelitian adalah untuk mendeskripsikan atau menjelaskan suatu fenomena.

\subsection{Waktu dan Tempat Penelitian}

Penelitian dilakukan mulai 02 November 2020 hingga 14 Desember 2020 selama 6 minggu. Waktu penelitian adalah Senin sampai Jumat pukul 08.00-16.00 WIB. Sabtu mulai pukul 08.00 hingga 12.00 WIB. Kuesioner dilakukan di beberapa kota besar di Provinsi Bangka Belitung untuk menilai keberhasilan pelaksanaan SLA.

\subsection{Subjek atau Target Penelitian}

Langkah penyelesaian dapat terdiri dari dua jenis desain, yaitu desain survei. Survei dilakukan dengan cara mengamati dan melakukan kuesioner kepada kedua belah pihak yaitu rekanan PLIK. Selain itu juga ada dari pihak mitra. Bagi mitra, pada dasarnya terdiri dari pertanyaan tentang seberapa cepat PLIK menanggapi pengaduan, peralatan apa saja yang sering rusak, dan seberapa tepat penanganan yang mereka lakukan. Adapun PLIK terdiri dari seberapa cepat mereka menangani masalah yang terjadi pada mitra, dan kendala apa yang menjadi kendala bagi mereka untuk segera mendatangi mitra yang melaporkan pengaduan.

\subsection{Prosedur Penelitian}

Dalam melakukan penelitian sebaiknya dibuatkan prosedur penelitian terlebih dahulu. Ini akan memandu kami dalam menentukan hasil yang diinginkan. Langkah-langkah prosedur 
penelitian antara lain mengidentifikasi masalah di lapangan. Setelah masalah teridentifikasi, langkah selanjutnya adalah merumuskan masalah agar lebih fokus, kemudian merumuskan hipotesis jika ada. Memilih pendekatan dengan menentukan variabel dan menentukan sumber data merupakan langkah selanjutnya sebelum mengembangkan instrumen yang valid. Setelah itu dilakukan pengumpulan data, sehingga selanjutnya data tersebut dapat dianalisis, diambil kesimpulannya dan langkah selanjutnya selesai. Berikut adalah prosedur penelitian yang dilakukan pada Gambar 2.

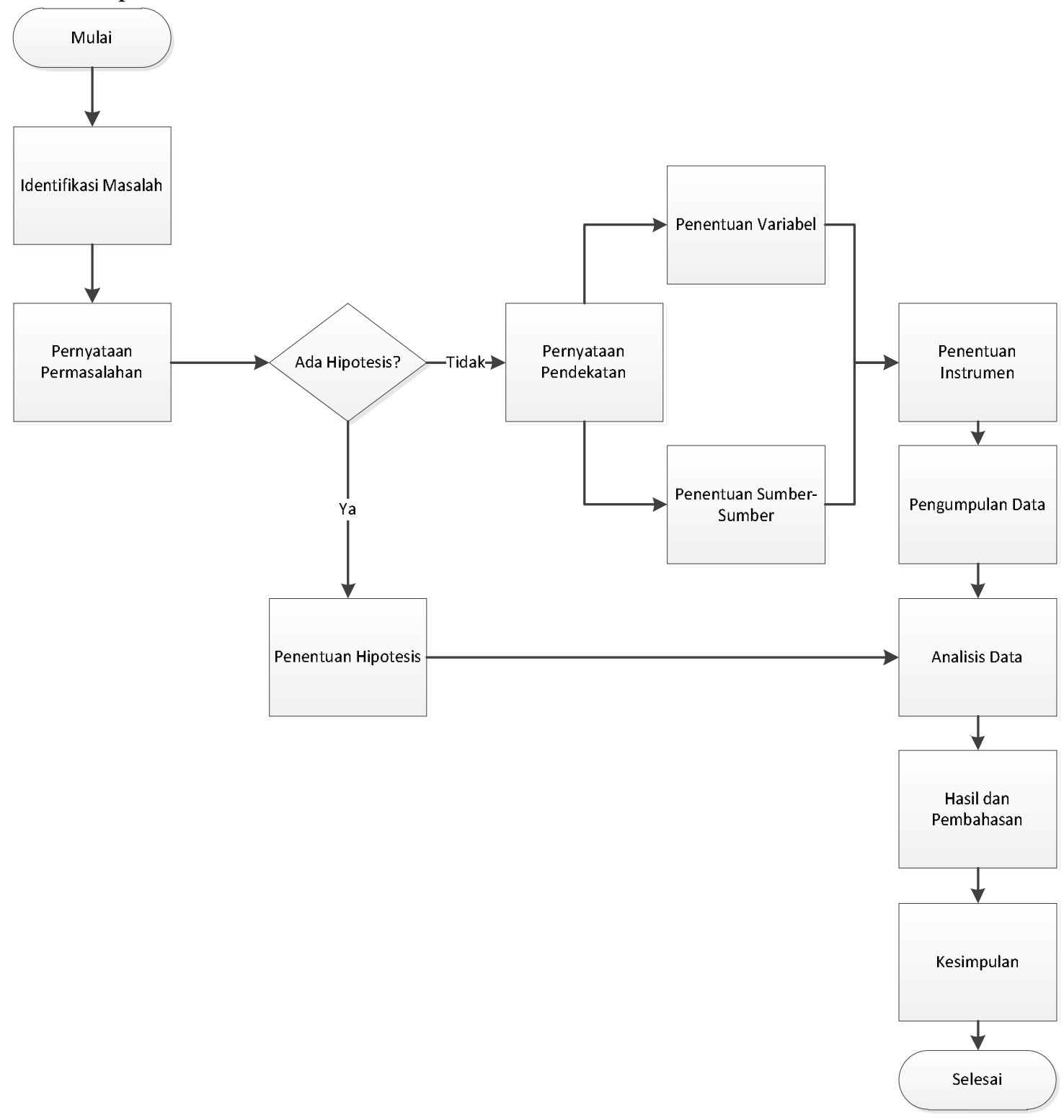

Gambar 2. Alur Prosedur Penelitian

\subsection{Data, Instrumen, dan Teknik Pengumpulan Data}

Model pengumpulan data dalam penelitian ini dilakukan dengan: 
a. Sebuah. Observasi, data penelitian langsung pada objek penelitian dengan mempelajari halhal yang berkaitan dengan pengelolaan data di PLIK masing-masing Kota Besar di Provinsi Bangka Belitung.

b. Angket, merupakan metode angket yang meliputi angket kesadaran manajemen dan angket tingkat kematangan.

c. Wawancara dilakukan dengan narasumber dengan menyusun pedoman tertulis tentang apa yang ditanyakan tentang masalah yang diteliti yang tidak tertuang dalam kuesioner.

\subsection{Teknik Analisa Data}

Setelah data diperoleh dan terkumpul, selanjutnya data tersebut akan diolah dengan Framework COBIT 4.0 untuk mengetahui hasilnya nantinya dengan standar Control Objective pada masing-masing variabel domain Delivery and Support. Skala dalam penentuan model kematangan terdiri dari:

- 0-Tidak Ada

- 1-Inisial / Ad Hoc

-2-Repeatable tapi Intuitif

-3-Didefinisikan

- 4-Dikelola dan Terukur

-5-Dioptimalkan

\section{HASIL DAN PEMBAHASAN}

\subsection{Survei Mitra PLIK}

Proses evaluasi dilakukan terhadap rekanan PLIK dimulai dengan pembuatan rencana kerja yang berisi penjelasan tahapan-tahapan untuk mendapatkan data yang dibutuhkan dengan berbagai teknik yang dibutuhkan seperti angket, wawancara dan observasi. Tabel 1 adalah data dari mitra PLIK di Provinsi Bangka Belitung. Dimana jumlah seluruh mitra berdasarkan kecamatan untuk tiap kabupaten kota adalah 46 kecamatan. Dimana setiap satu kabupaten memiliki peserta yang berbeda-beda. Total partisipan yang diamati dan diwawancarai sebanyak 512 orang.

Tabel 1. Sebaran Mitra PLIK Bangka Belitung

\begin{tabular}{clc}
\hline No. & \multicolumn{1}{c}{ Mitra } & Wilayah \\
\hline 1. & Kota Pangkalpinang & 7 \\
\hline 2. & Kabupaten Bangka & 8 \\
\hline 3. & Kabupaten Bangka Tengah & 6 \\
\hline 4. & Kabupaten Bangka Selatan & 8 \\
\hline 5. & Kabupaten Bangka Barat & 5 \\
\hline 6. & Kabupaten Belitung & 5 \\
\hline 7. & Kabupaten Belitung Timiur & 7 \\
\hline Jumlah & & 46 \\
\hline
\end{tabular}

Proses evaluasi pada PLIK menggunakan Framework COBIT 4.0 dengan fokus pada domain Delivery and Support. Untuk mendukung pencapaian target penelitian dilakukan dua tahap yaitu tahap perencanaan solusi dan tahap estimasi solusi. Fase perencanaan solusi dilakukan dengan tiga cara, yaitu menentukan tingkat kematangan untuk setiap tujuan pengendalian, kemudian menentukan pengujian hipotesis, dan menganalisis celahnya. 


\subsection{Diagram RACI}

Grafik RACI yang terdiri dari Responsible, Accountable, consulted dan atau Informed, merupakan empat parameter yang digunakan dalam matriks dalam menentukan pengambilan keputusan. Alat grafik RACI menguraikan kegiatan-kegiatan yang dilakukan dalam suatu organisasi, dalam hal ini PLIK terhadap mitranya. Berikut penjelasan dari masing-masing bidang yang harus ada di PLIK untuk mengetahui grafik RACI, untuk lebih jelasnya bisa dilihat pada Tabel 2:

a. Identifikasi beban kerja yang telah ditugaskan kepada karyawan atau departemen tertentu,

b. Pastikan prosesnya tidak lagi terlihat,

c. Pastikan anggota baru dijelaskan tentang peran dan tanggung jawab,

d. Temukan keseimbangan yang tepat antara lini proyek dan tanggung jawab,

e. Bagikan pekerjaan antar kelompok untuk menyelesaikan pekerjaan lebih cepat,

f. Bersikaplah terbuka untuk menyelesaikan konflik dan diskusi, dan

g. Mendokumentasikan peran dan tanggung jawab orang-orang di perusahaan atau organisasi.

Bidang-bidang yang ada di PLIK Bangka Belitung adalah sebagai berikut:

a. Administrasi: Merapikan pengarsipan, verifikasi data lewat telepon, validasi data Speedy dan akun rekanan, memperbarui data rekanan setiap ada perubahan.

b. Koordinator area: pemantauan situs.

c. Help Desk: menerima masukan dan keluhan dari partner, menginformasikan partner tentang notifikasi, meneruskan laporan ke teknisi.

d. Teknisi: pemeliharaan perangkat keras dan perangkat lunak, pemeliharaan alat rekanan, pengadaan stok barang.

e. Helper: membantu tugas teknisi.

f. Tim survei: pemantauan lokasi jika ada lokasi mitra tambahan atau perpindahan ke lokasi lain.

g. Keuangan (Keuangan): memastikan pendanaan tersedia bahkan di saat-saat darurat.

h. Warehouse: memastikan stock barang selalu ada, mengembalikannya kembali jika ada peralatan yang aus atau rusak.

i. Pengiriman (Shipping): pengiriman peralatan yang dibutuhkan rekanan dari gudang.

Tabel 2. Diagram RACI

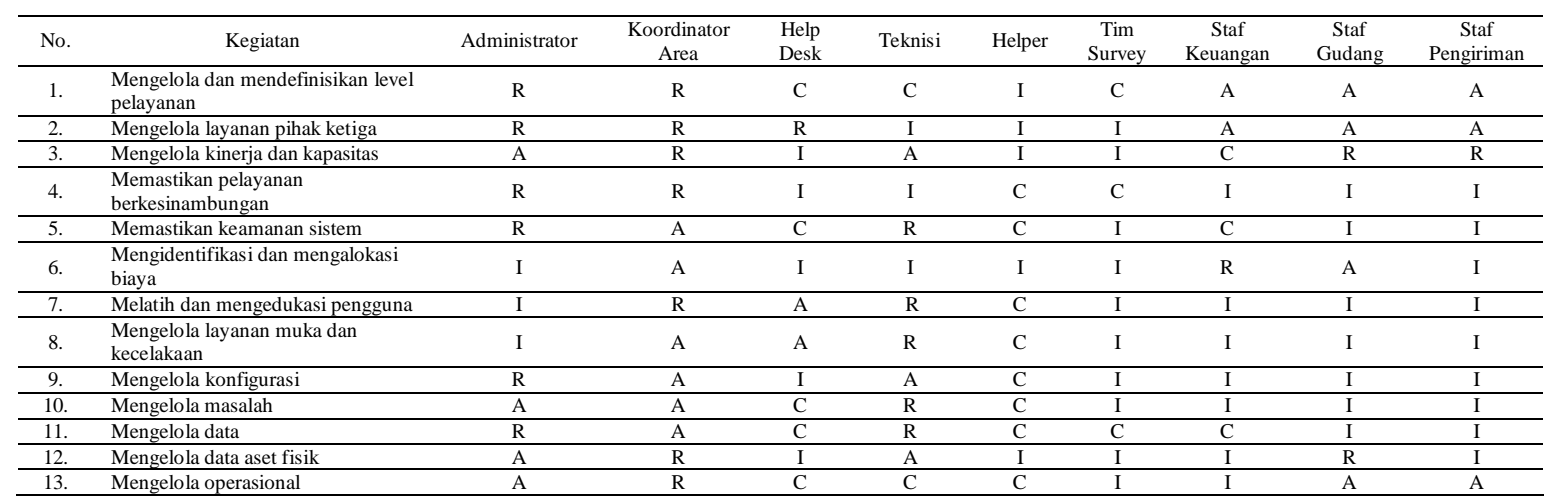

Dilihat dari tabel 2, maka jelas bahwa pembagian setiap aktifitas memiliki peranannya masing-masing, baik itu secara tanggung jawab secara penuh, ditugaskan atau diberikan 
perintah, diinformasikan bahkan hanya sebatas sekedar tahu saja dalam melakukan suatu aktifitas mereka masing-masing.

\subsection{Model Kematangan}

Setelah mendapatkan hasil instrumen survei, langkah selanjutnya adalah mendapatkan hasil jatuh tempo. Hasil kematangan ini kemudian menjadi hasil interpretasi akhir dari keberhasilan implementasi SLA di Mobil PLIK di Provinsi Bangka Belitung.

Tabel 3. Hasil Level Kematangan di Provinsi Bangka Belitung

\begin{tabular}{clcc}
\hline No. & \multicolumn{1}{c}{ Mitra } & Rata-rata & Level Kematangan \\
\hline 1. & Kota Pangkalpinang & 4,0 & 4 \\
\hline 2. & Kabupaten Bangka & 4,0 & 4 \\
\hline 3. & Kabupaten Bangka Tengah & 4,0 & 4 \\
\hline 4. & Kabupaten Bangka Selatan & 3,5 & 4 \\
\hline 5. & Kabupaten Bangka Barat & 3,5 & 4 \\
\hline 6. & Kabupaten Belitung & 3,2 & 3 \\
\hline 7. & Kabupaten Belitung Timur & 3,2 & 3 \\
\hline
\end{tabular}

Dalam domain Deliver and Support (DS), ada lima kabupaten yang berada di level Managed, yaitu Pangkalpinang, Bangka, Bangka Tengah, Bangka Selatan, dan Bangka Barat. Hal ini menunjukkan bahwa manajemen telah memantau dan mengukur kesesuaian prosedur dan mengambil tindakan jika proses tersebut tetapi tidak dapat dijalankan secara efektif. Proses ini terus mengalami peningkatan dan memberikan praktik yang baik. Otomatisasi dan alat digunakan dalam batasan tertentu. Belitung dan Belitung Timur berada pada level Defined, yang menunjukkan bahwa prosedur telah dibakukan, didokumentasikan, kemudian dikomunikasikan melalui pelatihan dan diamanatkan bahwa proses tersebut harus diikuti. Namun, penyimpangan tidak dapat dideteksi. Prosedur itu sendiri tidak lengkap tetapi meresmikan praktik saat ini.

Berdasarkan evaluasi yang telah dilakukan pada proses Define and Support berada pada Maturity Level 4 yaitu Managed. Perusahaan dalam hal ini PLIK yang berada di Provinsi Bangka Belitung selama ini telah melakukan pengukuran untuk mengetahui sejauh mana pelayanan yang diberikan PLIK kepada mitranya telah diterima oleh pelanggan dan dikelola dengan baik. Wewenang yang diberikan oleh PLIK kepada Help Desk dengan melakukan beberapa proses dinilai agak mengganggu, namun sejauh ini tidak menjadi masalah bagi PLIK itu sendiri. Kesimpulannya disini dapat ditarik bahwa PLIK Bangka Belitung Provinsi telah merencanakan dengan matang level 4 untuk para mitranya agar tercipta tingkat pelayanan yang baik.

\section{KESIMPULAN}

Service Level Agreement (SLA) tidak terlepas dari bagian Service Level Management (SLM) suatu lembaga atau perusahaan atau organisasi yang berperan sebagai kesepakatan antara penyedia dan pengguna untuk menentukan tingkat kedewasaan. Dilihat dari sudut pandang teknisi, teknisi telah melaksanakan tugasnya dengan baik, hanya masalahnya adalah kurangnya sumber daya manusia (SDM) yang membuat teknisi terkadang tidak dapat memenuhi SLA yang ada, hal ini menyebabkan banyak partner dari PLIK menunggu masalah yang mereka hadapi. segera ditangani, dan hal ini dapat berisiko menimbulkan masalah baru dan tentunya mengurangi rasa pelayanan kepada mitra. 
Selain kendala sumber daya manusia (SDM), yang terpenting disini adalah setelah melakukan beberapa pengujian, pendanaan dengan cara apapun harus diperhatikan, karena tidak ada dana yang mencukupi, aspek lainnya otomatis terhenti, padahal aspek tersebut sudah siap. Dilihat dari perspektif mitra di PLIK, banyak mitra yang sudah paham dan paham apa fungsinya di sini untuk meluncurkan program PLIK. Dan untuk PLIK sendiri secara keseluruhan baik dalam penanganan dan pelayanan. Namun bisa terhambat jika mengalami kendala, maka kinerja untuk melayani pasangannya sangat terganggu.

\section{SARAN}

Saran yang dapat diambil PLIK disini adalah meningkatkan kinerja pelayanannya, jika memungkinkan menambah personilnya untuk memaksimalkan kinerjanya, dan pengaturan keuangan juga sangat penting untuk menunjang kinerja PLIK semua.

\section{DAFTAR PUSTAKA}

[1] Pradana, Harrizki Arie. 2017, Analyze The Effectiveness of Service Level Agreement (SLA) Toward Goods Delivery, SSRN Electronic Journal, 05(01), 323-332. https://doi.org/10.2139/ssrn.2789024.

[2] Prameswari, N. S. S. T. D. 2016, Nur Shabrina Prameswari, Jurnal Teknik ITS, 5(2).

[3] Firmansyah, A. 2017, Upaya Peningkatan SLA pada IT Service Management di PT Trikomsel Oke Tbk Berdasarkan Kerangka Kerja ITIL V3, SIGMA Jurnal Teknologi Pelita Bangsa, 6(2), 105-111.

[4] Pradana, H.A., Gede Putra Pertama, P. P., Sujono, Mayasari, M. S., Andrika, Y., Juniawan, F. P., \& Sylfania, D. Y. 2019, Audit of Provincial Library Information System Based on COBIT 4.1. 2019 1st International Conference on Cybernetics and Intelligent System, ICORIS 2019. https://doi.org/10.1109/ICORIS.2019.8874921.

[5] Supono, S. 2020, Model Penilaian Kapabilitas Proses Layanan Service Level Agreement (SLA) pada Cloud Computing, Jurnal Sains dan Informatika, 6(1), 62-71. https://doi.org/10.34128/jsi.v6i1.209.

[6] Waspada, I. 2012, Analisa Best Practice Service Level Management (Slm) Cisco Menggunakan Kriteria Kelengkapan dari Thomas Schaaf, Jurnal Masyarakat Informatika, 1(2), 1-10. https://doi.org/10.14710/jmasif.1.2.1-10.

[7] Haviluddin, Setyadi, H. J. S., Widagdo, P. P. W., \& Taruk, M. T. 2016, Perbandingan Fasilitas Cobit 4.0/4.1 dan Cobit 5 Frameworks: Studi Pengguna Berdasarkan Literatur, Prosiding Seminar Ilmu Komputer dan Teknologi Informasi, 1(1), 30-37.

[8] Pramono, A. 2017, Analisis Teknologi Informasi Menggunakan Framework COBIT 4.1 (Studi Kasus: LMS SMK Negeri 2 Kediri), Journal Speed, 9(2), 42-49. 
[9] Pribadi, Muhammad Rizky. 2015, Penerapan Tata Kelola Teknologi Informasi Dengan Menggunakan COBIT Framework 4.1 (Studi Kasus pada RSUD Bari Palembang), Eksplora Informatika, 4(2), 115-124.

[10] Lusiana, D. 2017, Mengevaluasi Tingkat Kematangan Domain Delivery Support (DS11) Perpustakaan Menggunakan Kerangka COBIT 4.1, Jurnal Sistem \& Teknologi Informasi Indonesia, 2, 67-74. Retrieved from http://garuda.ristekbrin.go.id/documents/detail/1286512.

[11] M. R. Pribadi and H. Irsyad. 2018, Model Konseptual Penerapan Tata Kelola TI PLN Pembangkitan Sumbagsel Berdasarkan COBIT 5, Jurnal Ilmiah Informatika Global, 9(1), 20-25. 